\title{
INTEGRATED PLANNING FOR WASTEWATER TREATMENT AND RECYCLING FOR A SMALL COMMUNITY DEVELOPMENT
}

\author{
Ron Crites* \\ *Brown and Caldwell \\ 202 Cousteau Place, Suite 170 \\ Davis, California 95616
}

\begin{abstract}
Integrated water resources planning was conducted for Olowalu Town, a proposed development in western Maui, Hawaii. Total water needs, which can be supplied by a combination of diverted surface water, well water, recycled water and captured stormwater, are estimated at between 1 and $2 \mathrm{mgd}$. The Olowalu development will generate approximately 0.5 million gallons per day (mgd) of municipal wastewater. That wastewater can be recycled for beneficial use and irrigate between 80 and 120 acres depending on the amount of storage provided and the type of water reuse.
\end{abstract}

\section{KEYWORDS}

Water reuse, integrated water planning, decentralized treatment, distributed reuse.

\section{INTRODUCTION}

A new development is being proposed by Olowalu Town, LLC in West Maui, Hawaii. The project site is approximately 4 miles south of Lahaina and comprises approximately 700 acres of the Olowalu area. The site was previously used as a sugar cane plantation.

Brown and Caldwell estimated that the potable water demand will be approximately $0.6 \mathrm{mgd}$. This value represents the typical drinking water quality demand for inside residential/commercial use and is based on 1,500 residential units with a per unit daily usage of 400 gallons. Typical nonpotable usage for outside water use, including irrigation, assumes 150 to 400 acres of irrigated area and a nonpotable demand ranging from 600 to $1,600 \mathrm{acre}-\mathrm{ft} / \mathrm{yr}$ or 0.5 to $1.4 \mathrm{mgd}$ (Brown and Caldwell, 2005).

A typical wastewater flow per capita in Maui is 137 gallons per day (gal/d). For the ultimate 1,500 residences and a typical 2.5 persons per residence, the daily wastewater generation would be approximately $500,000 \mathrm{gal} / \mathrm{d}$ or $0.5 \mathrm{mgd}$. For purposes of this evaluation an expected average daily flow of $0.5 \mathrm{mgd}$ was used. 


\section{WATER SUPPLY ALTERNATIVES}

The water supply alternatives for the development include stream diversion and groundwater. Historically, the sugar cane plantation was irrigated with surface water diverted from Olowalu stream, which flows into the ocean and has cultural value as a flowing stream. Other sources of supply for nonpotable demands include recycled water and captured stormwater.

Olowalu is on the arid side of the island, so an integrated water supply is envisioned as being environmentally sound. The groundwater aquifer has at least a $3 \mathrm{mgd}$ capacity and could supply the potable water demands of the project. The stream diversion used in the past has more than enough flow capacity for the potable needs but conflicts with the cultural value placed on a flowing stream as a fishery.

To minimize the diversion of stream flow, the potable supply would focus on groundwater while the nonpotable supply would be provided by a combination of recycled water and captured stormwater. Storage of recycled water and stormwater would be used to meet dry season nonpotable demands.

\section{WASTEWATER TREATMENT ALTERNATIVES}

Wastewater will be managed onsite for individual residential lots in the low density areas provided that at least 0.25 acres are available on the lot. For medium density residential areas, the wastewater will be treated in interceptor tanks and collected using effluent sewers. Effluent sewers, primarily small diameter gravity sewers, will be utilized by following the terrain of the former plantation and having a minimal depth of burial. For this case, treatment of wastewater will occur in cluster systems using recirculating gravel filters, vertical flow wetlands, or biotextile filters, and then filtered through cloth filters, disinfected and reused locally.

\section{Recirculating Gravel Filters}

The recirculating gravel filter (RGF) evolved from the intermittent sand filter (ISF), in order to achieve better control of the dosing for higher rates. The filter medium usually consists of fine gravel. The RGF has been used for flow rates up to $1.0 \mathrm{mgd}$. The RGF is commonly used to treat septic tank effluent. They have also been used prior to ultraviolet (UV) disinfection for water reuse (Crites, et al., 1997).

The operation is similar to the ISF with the exception of a portion of the treated effluent which is returned to a recirculation tank where it is used to dilute the incoming effluent. By diluting the effluent higher application rates can be used. A schematic of a RGF is shown in Figure 1.

The RGF bed can be one third the size of an ISF for treating the same flow. An added expense comes from the additional recirculating tank. Although gravel media is more expensive than sand, the expected life for the media is longer and it will not clog from biological growth if properly designed and operated. 


\section{Figure 1 - Schematic Flow Diagram of Recirculating Gravel Filter} (Crites and Tchobanoglous, 1998)

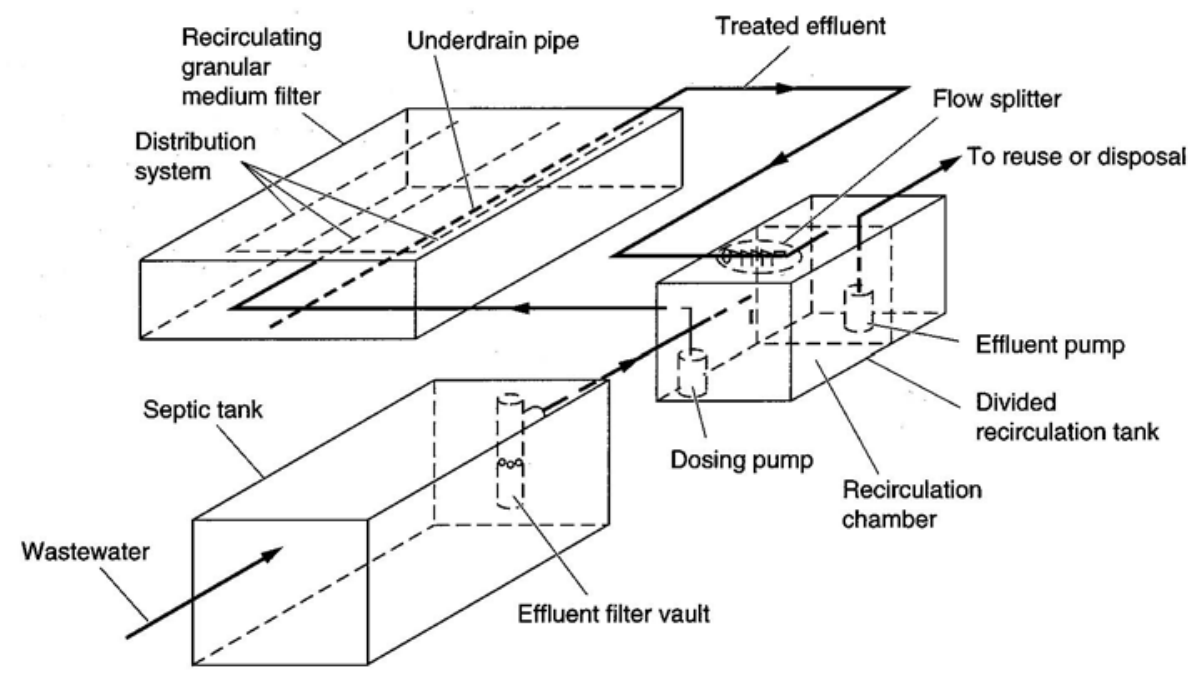

\section{Vertical Flow Wetlands}

Vertical flow wetlands are similar to recirculating gravel filters (see Figure 2), except that emergent plants are added to the surface. Primary effluent (usually from a septic tank) is required prior to discharge to the vertical flow wetlands. Treatment occurs as the water percolates through the sand and gravel to the underdrains. A schematic of a vertical flow wetlands is shown in Figure 2.

Vertical flow wetlands will achieve advanced secondary effluent quality. The vertical flow wetlands effluent will be nitrified and contain less than $10 \mathrm{mg} / \mathrm{L}$ of biochemical oxygen demand (BOD) and total suspended solids (TSS). They have been used in Europe for many years and recently in North America to achieve secondary treatment. To achieve Hawaii water reuse standards, sand filtration and UV disinfection need to be added. Hawaii requires the effluent from filtration to contain less than 2 units of turbidity at all times. 
Figure 2 - Sketch of a Vertical Flow Constructed Wetland

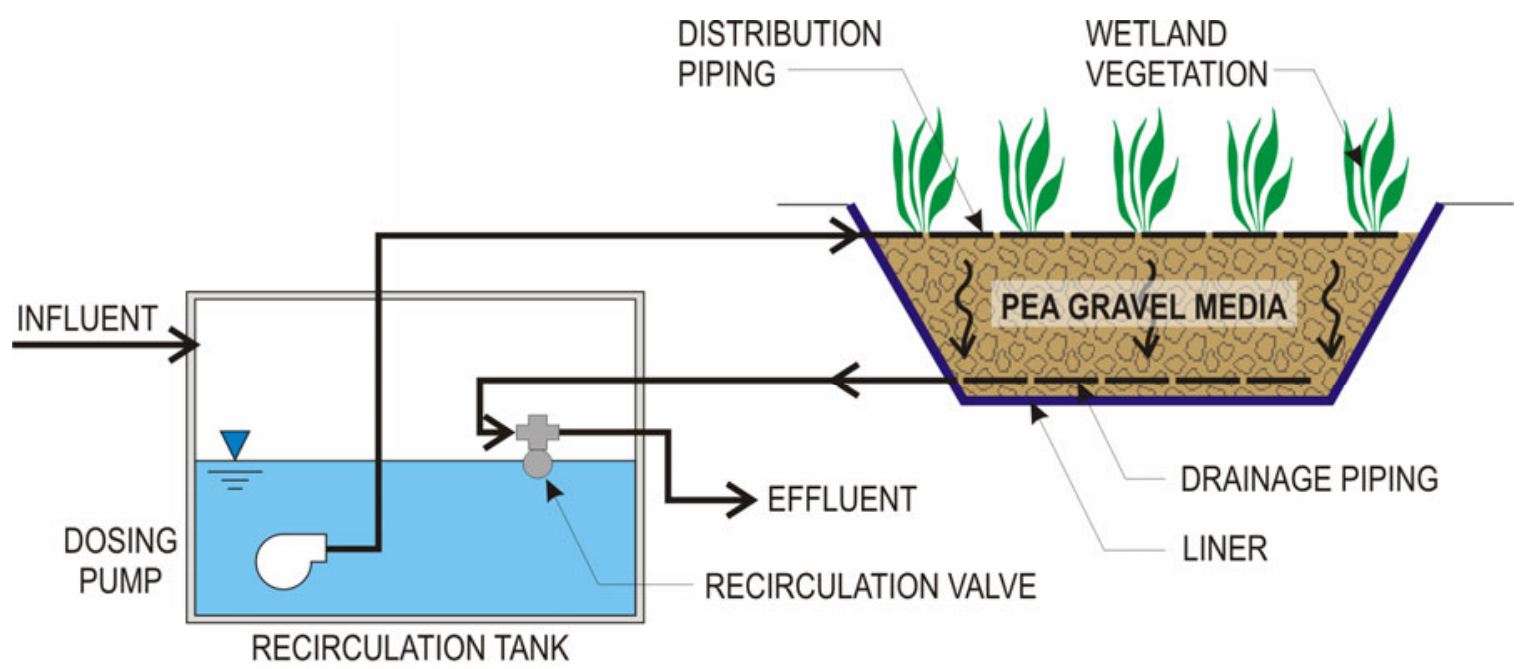

VERTICAL FLOW WETLAND

\section{Biotextile filter}

The biotextile filter (also known as the textile bioreactor) was developed as an alternative to sand and gravel filters. They use non-woven textile chips (small pieces of cut textile with greater than 80 percent pore space) instead of a granular medium. Because of the large pore space of the textile chips, hydraulic loading rates can be increased significantly, thus reducing space requirements for the filter. The textile filter can operate as a single-pass or a recirculating filter. A schematic of a textile packed-bed filter is shown in Figure 3.

The largest pre-fabricated biotextile filter made is a 2,500 gpd system by Orenco called the Advantex 100. An installation of 45 units in parallel is operational for a flow of 112,500 gpd. The solids trapped in the media will build up, but the expected life of the media is 3 to 5 years. Because the textile chips are inert, the media can be rinsed and then reused.

\section{High Density Options}

For the high density areas, two alternative systems for wastewater treatment were evaluated: 1) the membrane bioreactor (MBR) and 2) the vertical flow wetlands. If the entire development is sewered to a centralized treatment site. a $0.5 \mathrm{mgd}$ treatment system would be needed. The area needed would range from 0.5 acres for the MBR alternative to 1.6 acres for the vertical flow wetlands alternative. 
Figure 3 - Schematic of a Biotextile Filter: Advantex Filter from Orenco Systems, Inc. showing (1) monitoring system, (2) processing tank, (3) biotube pumping package, (4) Advantex filter, and (5) recirculating splitter valve.

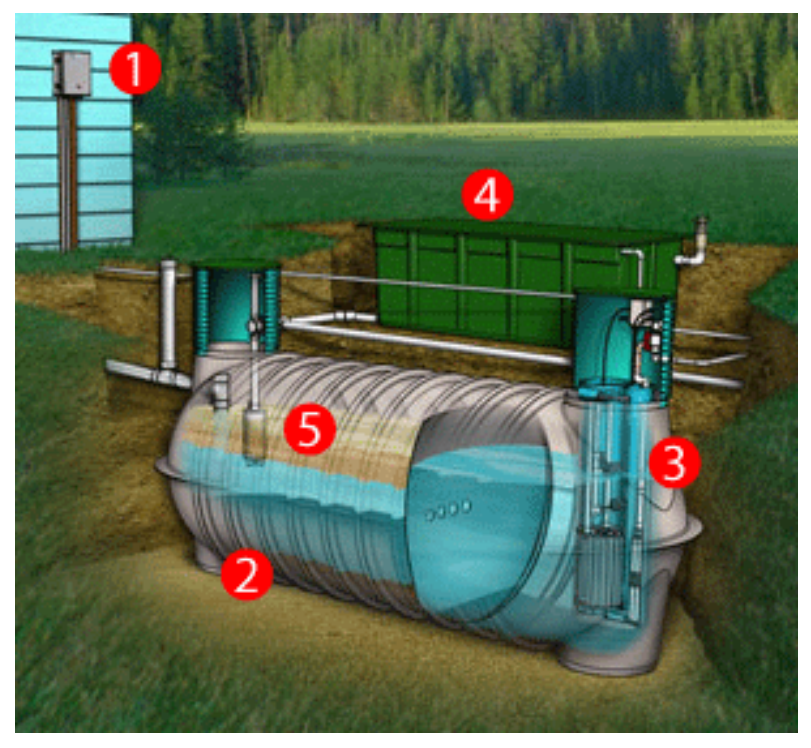

\section{Land Requirements}

Because of the high value of land on the island, the amount of land required for wastewater treatment was determined to be a significant criterion for evaluating alternatives. The area required for treatment for each of the technologies is presented in Table 2 including the footprint for a 0.5 mgd facility.

Table 2 - Summary of Area Requirements for Treatment Options

\begin{tabular}{l|c|c}
\hline \hline \multicolumn{1}{c|}{ Treatment Option } & $\begin{array}{c}\text { Area required, square feet } \\
\text { per gallon }\end{array}$ & $\begin{array}{c}\text { Approximate site area for } \\
\text { a 0.5 mgd facility, acres }\end{array}$ \\
\hline Individual onsite leachfields & 9.0 & -- \\
\hline Recirculating gravel filters & 0.20 & -- \\
\hline Biotextile filters (Advantex) & 0.09 & -- \\
\hline Vertical flow wetlands & 0.14 & 1.6 \\
\hline MBR & 0.04 & 0.5 \\
\hline
\end{tabular}

\section{Water Recycling Options}

The potential uses of recycled water for the Olowalu project include landscape irrigation, crop irrigation, water source for green waste composting, dust control, and construction water. Maui County is a leader in Hawaii water recycling with many successful reuse projects. A summary of recycled water projects on Maui is presented in Table 3. 
Table 3 - Summary of Water Recycling Projects on Maui

\begin{tabular}{l|l|c}
\hline \hline \multicolumn{1}{c|}{ Project } & \multicolumn{1}{|c}{ Description } & Average flow, mgd \\
\hline Monsanto Seed Corn & Agricultural reuse near Kihei & 0.22 \\
\hline Monsanto facility at Kihei & $\begin{array}{l}\text { Landscape irrigation, fire control, } \\
\text { toilet/urinal flushing }\end{array}$ & 0.015 \\
\hline $\begin{array}{l}\text { Piilani schools, gardens } \\
\text { and common areas }\end{array}$ & $\begin{array}{l}\text { Landscape irrigation of } \\
\text { schoolyards, medians and road } \\
\text { shoulders }\end{array}$ & 0.2 \\
\hline Bioreal, Inc. & Cooling of biodomes & 0.1 \\
\hline Kaanapali resort & $\begin{array}{l}\text { Golf course and landscape } \\
\text { irrigation }\end{array}$ & 1.2 \\
\hline Kihei & Golf course irrigation & 0.5 \\
\hline Lanai & Golf course irrigation & 0.25 \\
\hline $\begin{array}{l}\text { Kahului, Kanaha Cultural } \\
\text { Park }\end{array}$ & $\begin{array}{l}\text { Native Hawaiian plants and } \\
\text { coconut trees }\end{array}$ & 0.02 \\
\hline
\end{tabular}

\section{Integrated Water Resources Planning}

A significant issue is the diversion of stream flow in the future because of concern about Hawaiian cultural practices. Keeping the stream flowing has great cultural and historical value. Past land use has included a sugar cane plantation where over 700 acres were irrigated and much of the stream flow was diverted for that use. Therefore, if the municipal water supply can be supplied by groundwater and if recycled water can supply a portion of the outdoor water needs for irrigation, the current amount of stream flow diverted for irrigation may be able to be reduced. The range of water needs that could be supplied from each source is shown graphically in Figure 4.

\section{RESULTS}

In November 2005 an intensive town planning effort was conducted, led by the town planners DPZ. The town planners constructed alternative designs that divided approximately 1,500 residences into 3 pedestrian sheds. A pedestrian shed is a neighborhood in which a person can walk from the edge to the center of the neighborhood in 5 minutes. Indoor municipal water supply would be provided from the sustainable yield of the groundwater. A water recycling facility would be located in each of the 3 town areas near the largest demand for water recycling. Storage for non-irrigation periods would be incorporated into existing and future reservoirs. The exact size and location of the storage reservoirs was deferred until later in the planning process. For very wet conditions, a backup disposal system consisting of an injection well is planned. 
Figure 4 - Diagram of Sources of Supply Water for Olowalu Development (Brown and Caldwell, 2005)

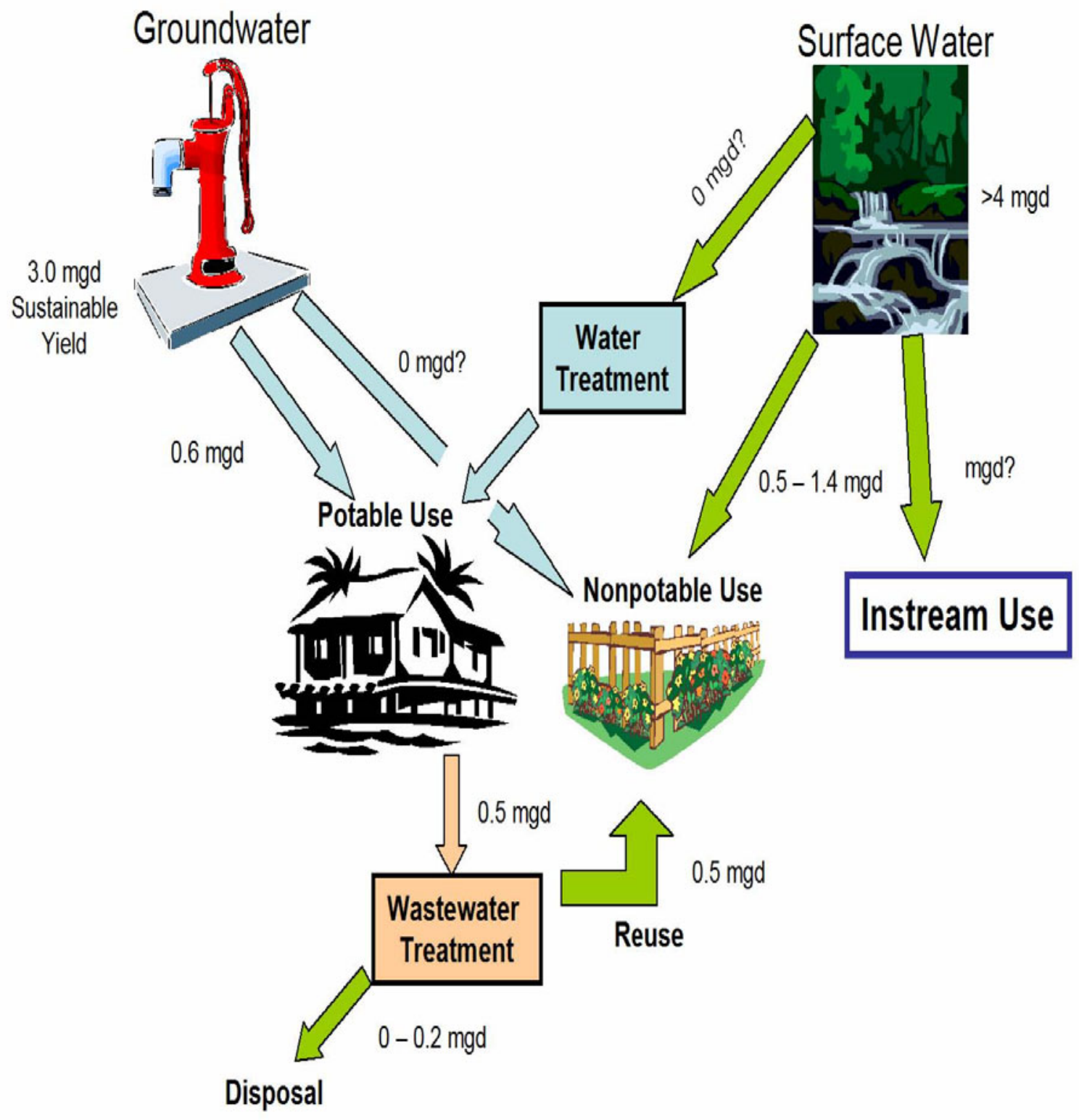

The planning objectives for stormwater would be to avoid erosion and keep developed-condition peak storm runoff to levels experienced pre-development. Low impact development practices would be followed to maximize storage and infiltration of peak flows and provide solids removal to the stormwater that returns to the stream. Stormwater would be treated in detention basins and reused to irrigated playgrounds and open spaces. Some portion of the stormwater will be returned to the stream to allow it to flow to the ocean. Overall, the project would make appropriate use of all four sources of water for this sustainable development. 


\section{CONCLUSIONS}

Integrated water resources planning resulted in appropriate use and reuse of water resources for the Olowalu project. To accommodate the cultural value placed on a flowing stream, groundwater was selected as the sources for potable supplies. For non-potable uses the combination of recycled water, captured stormwater and minimal use of flows from Olowalu stream was preferred.

Recycled water will be provided by three separate decentralized water recycling facilities. For the two residential neighborhoods, the vertical flow wetlands are preferred. For the densely populated town center, an MBR facility is favored.

\section{REFERENCES}

Brown and Caldwell (2005) Olowalu Water and Wastewater Options Report, prepared for Frampton and Ward, Maui. October 28, 2005.

Crites, R.W., C. Lekven, S. Wert, and G. Tchobanoglous. (1997). A Decentralized Wastewater System for a Small Residential Development in California. The Small Flows Journal.Vol. 3, Issue 1, Morgantown, WV.

Crites, R.W., and G. Tchobanoglous. (1998). Small and Decentralized Wastewater Management Systems. McGraw-Hill, New York, NY. 